\title{
RESEARCH
}

Open Access

\section{Conditioned media from endothelial progenitor cells cultured in simulated microgravity promote angiogenesis and bone fracture healing}

Lingchi Kong ${ }^{1,2+}$, Yan Wang ${ }^{2 \dagger}$, Haixing Wang ${ }^{2}$, Qi Pan ${ }^{2}$, Rongtai Zuo ${ }^{1}$, Shanshan Bai ${ }^{2}$, Xiaoting Zhang ${ }^{2}$, Wayne Yukwai Lee ${ }^{2}$, Qinglin Kang ${ }^{1 *}$ and Gang Li $i^{2,3,4^{*}}$ (i)

\begin{abstract}
Background: Paracrine signaling from endothelial progenitor cells (EPCS) is beneficial for angiogenesis and thus promotes tissue regeneration. Microgravity (MG) environment is found to facilitate the functional potentials of various stem or progenitor cells. The present study aimed to elucidate the effects of MG on pro-angiogenic properties and fracture repair capacities of conditioned media (CM) from EPCs.

Methods: Human peripheral blood-derived EPCs were cultured under MG or normal gravity (NG) followed by analysis for angiogenic gene expression. Furthermore, the serum-free CM under MG (MG-CM) or NG (NG-CM) were collected, and their pro-angiogenic properties were examined in human umbilical vein endothelial cells (HUVECs). In order to investigate the effects of MG-CM on fracture healing, they were injected into the fracture gaps of rat models, and radiography, histology, and mechanical test were performed to evaluate neovascularization and fracture healing outcomes.
\end{abstract}

Results: MG upregulated the expression of hypoxia-induced factor-1a (HIF-1a) and endothelial nitric oxide synthase (eNOS) and promoted NO release. Comparing to NG-CM, MG-CM significantly facilitated the proliferation, migration, and angiogenesis of HUVECs through NO-induced activation of FAK/Erk1/2-MAPK signaling pathway. In addition, MG-CM were verified to improve angiogenic activities in fracture area in a rat tibial fracture model, accelerate fracture healing, and well restore the biomechanical properties of fracture bone superior to NG-CM.

Conclusion: These findings provided insight into the use of MG bioreactor to enhance the angiogenic properties of EPCs' paracrine signals via HIF-1a/eNOS/NO axis, and the administration of MG-CM favored bone fracture repair.

Keywords: Endothelial progenitor cells, Microgravity, Conditioned media, Angiogenesis, Fracture healing

\footnotetext{
* Correspondence: orthokang@163.com; gangli@cuhk.edu.hk

${ }^{+}$Lingchi Kong and Yan Wang contributed equally to this work.

'Department of Orthopaedic Surgery, Shanghai Jiao Tong University

Affiliated Sixth People's Hospital, Yishan Rd. 600, Shanghai 200233, People's

Republic of China

2Department of Orthopaedics \& Traumatology, Stem Cells and Regenerative

Medicine Laboratory, Li Ka Shing Institute of Health Sciences, Faculty of

Medicine, The Chinese University of Hong Kong, Prince of Wales Hospital,

Shatin, Hong Kong SAR PRC

Full list of author information is available at the end of the article
}

(c) The Author(s). 2021 Open Access This article is licensed under a Creative Commons Attribution 4.0 International License, which permits use, sharing, adaptation, distribution and reproduction in any medium or format, as long as you give appropriate credit to the original author(s) and the source, provide a link to the Creative Commons licence, and indicate if changes were made. The images or other third party material in this article are included in the article's Creative Commons licence, unless indicated otherwise in a credit line to the material. If material is not included in the article's Creative Commons licence and your intended use is not permitted by statutory regulation or exceeds the permitted use, you will need to obtain permission directly from the copyright holder. To view a copy of this licence, visit http://creativecommons.org/licenses/by/4.0/. The Creative Commons Public Domain Dedication waiver (http://creativecommons.org/publicdomain/zero/1.0/) applies to the data made available in this article, unless otherwise stated in a credit line to the data. 


\section{Background}

Bone fracture caused mainly by accidents or sports injuries is a common clinical emergency [1]. Unfortunately, systemic diseases or other factor-induced delayed union or nonunion that requires repeated treatment occur in a significant proportion of this population $[2,3]$. Therefore, treatment means exploration for accelerating bone regeneration is needed to relieve this predicament. Bone fracture repair is a complex process of triggering endogenous regenerative procedures to restore bone structure [1], in which neovascularization always plays crucial roles in maintaining sufficient blood supply, especially at the stage of primitive callus formation [4]. Newly formed blood vessels are in charge of transporting oxygen, nutrients, numerous cell types, and cytokines to the injury site for tissue repair. As such, the importance of modulating vascularization at fracture sites for better fracture healing is widely accepted as a new treatment option which is under extensive investigation.

Endothelial progenitor cells (EPCs) are cell populations mainly derived from bone marrow, circulate in peripheral blood, and assemble into injury site to enhance vascular repair in pathological conditions [5]. EPCs contribute to neovascularization through differentiation into mature endothelial cells [6] and paracrine manners to trigger a series of angiogenic events [7], which turns EPCs into an attractive candidate for treating stroke [8], diabetic foot [9], and traumatic bone defects [10]. However, the success of clinical application is seriously limited due to several risks including embolism formation, immunogenicity, and malignant transformation [11]. Importantly, it is reported that cell-free administration of EPCs' derivatives including exosomes or conditioned media $(\mathrm{CM})$ is as effective alternative as cell transplantation for promoting tissue revascularization and functional recovery [12-14]. There are substantial biological factors derived from EPCs including angiogenic mRNAs, microRNAs, proteins, and chemical molecules in $\mathrm{CM}$. Of note, endogenous nitric oxide (NO), as a paracrine pro-angiogenic signaling molecule, is primarily synthesized by endothelial nitric oxide synthase (eNOS) and released from EPCs or mature endothelial cells during neovascularization $[15,16]$. It is well known that NO could improve EPCs' and endothelial cells' migration, angiogenesis, and resistance to apoptosis [17-19], and therefore, NO release contributes to the paracrine properties of EPCs during tissue neovascularization.

In recent years, space flight acquires rapid development and microgravity (MG) has been reported to improve proliferation and functions of various stem or progenitor cells $[20,21]$. Cardiovascular system is sensitive to gravity alteration [22, 23], and repair potentials of EPCs and endothelial cells are also influenced by MG $[24,25]$. In addition, a previous study demonstrated that
MG affected porcine blood-derived EPCs' differentiation into mature endothelial cells and eNOS/NO signals in a time-dependent manner with an unclear mechanism [22]. Considering that the paracrine factors of EPCs are crucial for angiogenesis and neovascularization, we assumed that increased NO release from EPCs after MG exposure may be achieved by eNOS upregulation, and $\mathrm{NO}$ as an important regulator played a crucial role in endothelial cells' angiogenesis.

The present study aimed to investigate the effects of MG on paracrine properties of EPCs and identify above hypothesis. After that, the in vitro functions of EPCderived CM modulated by MG in angiogenesis were explored, as well as the underlying mechanisms. Finally, a rat tibial fracture model was employed to examine the in vivo effects of $\mathrm{CM}$ on neovascularization and fracture healing.

\section{Methods \\ Isolation, culture, and identification of EPCs}

Human peripheral blood-derived EPCs were isolated from healthy volunteers aged 18 to 30 years old as previously described [26]. Written informed consent was obtained from all of the donors, and this study was approved by the Ethics Committees of Shanghai Jiao Tong University Affiliated Sixth People's Hospital. Briefly, peripheral blood mononuclear cells were isolated using Ficoll density gradient centrifugation according to the manufacturer's protocol, followed by washing with phosphate-buffered saline (PBS). The cells were plated in culture dishes pre-coated with fibronectin $\left(5 \mu \mathrm{g} / \mathrm{cm}^{2}\right)$ (Merck, Darmstadt, Germany) and cultured in endothelial basal medium 2 (EBM-2; Lonza, Basel, Switzerland) supplemented with EBM-2-MV-SingleQuots (Lonza). Cells were cultured at $37{ }^{\circ} \mathrm{C}, 5 \% \mathrm{CO}_{2}$ in a humidified environment, and non-adherent cells were removed after 3 days of culture. Medium was replaced every other day, and EPCs were passaged at $80-90 \%$ confluence. The cells at passage two were used in the following experiments. The morphology; cell markers including CD34, CD31, and von Willebrand factor (vWF); and angiogenic function of the remaining adherent cells were determined.

\section{Culture of human umbilical vein endothelial cells (HUVECs)}

HUVECs were purchased from ScienCell Corporation (Shanghai, China) and cultured in Dulbecco's modification of Eagle's medium (DMEM; Gibco, Grand Island, NY, USA) containing $10 \%(\mathrm{v} / \mathrm{v})$ fetal bovine serum (FBS; Gibco), 1\% (v/v) endothelial cell growth supplements (ECGS; Gibco), and 1\% (v/v) penicillin/streptomycin (P/ $\mathrm{S}$; Gibco) in a humidified atmosphere of $5 \% \mathrm{CO}_{2}$ at $37^{\circ} \mathrm{C}$. 


\section{MG simulation and $\mathrm{CM}$ collection}

To simulate MG, we used a newly developed Gravite ${ }^{\bullet}$ (Space Bio-Laboratories Co., Ltd., Hiroshima, Japan), which produces an environment similar to that of outer space by rotating the cells around two axes and integrating the gravity vector with the temporal axis [20]. A simulated condition of $10^{-3} \mathrm{~g}$ was generated and monitored by a gravity acceleration sensor. EPCs grown in T25 $\mathrm{cm}^{2}$ culture flasks were in the three-dimensional (3D) clinostat Gravite ${ }^{\circ}$ at $37^{\circ} \mathrm{C}$ in a $5 \% \mathrm{CO}_{2}$ chamber. The air bubbles in flasks were fully evacuated to eliminate the influence of shear stress.

CM from EPCs were generated as follows: $70 \%$ confluent cells were fed with serum-free DMEM and then exposed to MG (MG-CM) or normal gravity (NG-CM) for $24 \mathrm{~h}$. Cell debris was precipitated by centrifugation at $4{ }^{\circ} \mathrm{C}$ at $800 \times g$ for $10 \mathrm{~min}$. Supernatant was collected followed by filtration with $0.22-\mu \mathrm{m}$ filters and then stored at $-80^{\circ} \mathrm{C}$ until further use.

\section{Chemicals}

The NO scavenger Carboxy-PTIO was purchased from Beyotime Biotechnology Corporation (Shanghai, China) and worked at a concentration of $100 \mu \mathrm{M}$ for producing $\mathrm{NO}$ reduced MG-CM, the NO content of which was almost equivalent to NG-CM. The Erk1/2-MAPK selective inhibitor PD98059 was purchased from Cell Signaling Technology (Danvers, MA, USA) and applied at a concentration of $50 \mu \mathrm{M}$.

\section{Cell proliferation assay}

The EPCs or HUVECs were seeded in 96-well plates at an initial density of $4 \times 10^{3}$ cells per well. DMEM, NG$\mathrm{CM}$, and MG-CM with $10 \%$ FBS were added followed by determination with 3-(4,5-dimethylthiazol-2-yl)-2,5diphenyl tetrazolium bromide (MTT; Sigma-Aldrich, Saint Louis, MO, USA). At different time points, the cells were treated with MTT solution $(0.5 \mathrm{mg} / \mathrm{ml})$ for $4 \mathrm{~h}$ at $37^{\circ} \mathrm{C}$. After that, the dark blue formazan crystals formed in intact cells were solubilized with $100 \mu \mathrm{l} \mathrm{di-}$ methyl sulfoxide (DMSO). The absorbance was measured at $492 \mathrm{~nm}$ with a microplate reader.

\section{Quantitative real-time polymerase chain reaction (qRT- PCR)}

Total RNA was extracted using Trizol reagent (Invitrogen, Carlsbad, CA, USA). Complementary DNA synthesis was performed using PrimeScript RT reagent kit (Takara, Dalian, China) according to the manufacturer's instruction. Quantitative PCR for hypoxia-induced factor-1 $\alpha$ (HIF-1 $\alpha)$, eNOS, vascular endothelial growth factor (VEGF), matrix metalloproteinase-9 (MMP-9), platelet-derived growth factor-B (PDGF-B), and angiogenin-2 (Ang-2) was performed using the SYBR-
Green Master Mix Plus (Applied Biosystems, Foster City, CA, USA) with ABI 7900 HT System for 40 cycles. The primers were purchased from Invitrogen, and primer sequences are shown in Supplementary Table 1. The relative expression levels of genes were normalized to glyceraldehyde-3-phosphate dehydrogenase (GAPDH).

\section{Measurement of nitric oxide}

Nitrite concentrations in the culture media were measured as an indicator of NO production using the NO detection kit (Beyotime) in accordance with the manufacturer's protocol. Fifty microliters of medium and an equivalent amount of Griess reagent I and II were added per well. After mixing, the absorbance was measured at $540 \mathrm{~nm}$ with a microplate reader. NO levels in the media were calculated based on a standard curve.

\section{Cell migration assay}

Cell migration capacity was evaluated using a $8.0-\mu \mathrm{m}$ pore size-Transwell chambers (Corning, NY, USA). HUVECs $\left(2 \times 10^{4}\right.$ cells in $200 \mu \mathrm{l}$ DMEM or CM with $1 \%$ FBS) were loaded into the upper chamber, which was inserted into a 24-well plate with $500 \mu \mathrm{L}$ of DMEM complete medium in the well beneath. After $12 \mathrm{~h}$, cells that migrated across the transwell member were fixed with $4 \%$ paraformaldehyde (PFA; Sigma-Aldrich) and stained with $0.1 \%$ crystal violet (Solarbio, Beijing, China). The migration activity was quantified by counting the number of migrated cells under a light microscope (Nikon TE2000-E, Tokyo, Japan).

Scratch wound healing assay was also employed to determine cell migration. Briefly, HUVECs were seeded into a 6 -well plate. At $100 \%$ confluence, a $100-\mu \mathrm{l}$ pipette tip was used to make a straight scratch across the middle of each well. The cellular debris was rinsed away with PBS for twice and the cells were maintained in serumfree medium. At the time points of 0 and $12 \mathrm{~h}$, photographic images of each plate were acquired under a microscope (Nikon TE2000-E). The distance migrated was assessed using Image J software.

\section{Tube formation assay}

To perform the tube formation assay, 24-well plates were pre-coated with $150 \mu \mathrm{L}$ Matrigel (Corning). HUVECs $\left(1 \times 10^{5}\right.$ cells per well $)$ were then seeded into the plates and cultured with serum-free medium for $6 \mathrm{~h}$. The living cells were stained with Calcein-AM $(2 \mu \mathrm{g} / \mathrm{ml})$ (Solarbio) for $30 \mathrm{~min}$ at $37{ }^{\circ} \mathrm{C}$ and $5 \% \mathrm{CO}_{2}$. After the replacement of the medium containing dye with serumfree medium, capillary-like structures were observed under a fluorescence microscope (Nikon TE2000-E) and the capacity of tube formation was quantified by calculating the total length of tubes per field using Image $J$ software. 


\section{Immunofluorescence staining}

The HUVECs grown on cover slides were rinsed with PBS for three times and then fixed with 4\% PFA for 15 $\mathrm{min}$ at room temperature. After the sections were treated with $0.2 \%(\mathrm{v} / \mathrm{v})$ Triton X-100 in PBS for $10 \mathrm{~min}$, $3 \%(\mathrm{w} / \mathrm{v})$ bovine serum albumin (BSA; Sigma-Aldrich) was applied to block potential non-specific binding sites for $30 \mathrm{~min}$ at room temperature. The cells were then incubated with primary antibodies against Ki67 (Abcam, 1: 200, Cambridge, UK), CD31 (Abcam, 1: 200), CD34 (Abcam, 1: 150), or vWF (Abcam, 1: 200) overnight at $4{ }^{\circ} \mathrm{C}$. After being washed, the cells were incubated with secondary antibodies (Abcam, 1: 200) coupled with TRITC or Alexa Fluor 488 for $1 \mathrm{~h}$ at room temperature. The slides were then mounted by using ProLongTM Gold Antifade Mountant (Invitrogen) with 4,6-diamidino-2-phenylindole (DAPI).

\section{Western blot analysis}

Protein was extracted from cells using Radio Immunoprecipitation Assay (RIPA) lysis buffer (Sigma-Aldrich). Protein concentration was determined using the bicinchoninic acid (BCA) kit (Thermo Fisher, Waltham, MA, USA). Proteins were separated by $10 \%$ sodium dodecyl sulfate polyacrylamide gel electrophoresis (SDS-PAGE; Bio-Rad, Hercules, CA, USA) and then transferred onto polyvinylidene difluoride (PVDF) membrane (Bio-Rad). The membrane was blocked with $5 \%(\mathrm{w} / \mathrm{v})$ BSA at room temperature for $1 \mathrm{~h}$. Afterwards, the membrane was incubated with primary antibodies against HIF-1 $\alpha$ (Abcam, 1: 1500), eNOS (Abcam, 1: 1500), inducible nitric oxide synthase (iNOS; Cell Signaling Technology, 1: 1500), FAK (Cell Signaling Technology, 1: 2000), p-FAK (Cell Signaling Technology, 1: 1000), Erk1/2 (Cell Signaling Technology, 1: 2000), p-Erk1/2 (Cell Signaling Technology, 1: 1000), and GAPDH (Santa Cruz, 1: 2000, Heidelberg, Germany) at $4{ }^{\circ} \mathrm{C}$ overnight followed by incubating with secondary antibodies (Abcam, 1: 2000) at room temperature for $1 \mathrm{~h}$. Thereafter, the proteins were visualized using Immun-Star ${ }^{\text {ma }}$ HRP Chemiluminescent Kit (Bio-Rad).

\section{Rat fracture model}

All animal experiments were approved by the Animal Research Committee of Shanghai Jiao Tong University Affiliated Sixth People's Hospital. Forty-five 12-week-old male Sprague-Dawley rats were used to generate stabilized tibial fracture models and then randomly assigned to the DMEM (control), NG-CM, or MG-CM groups ( $n=15$ per group). The animal experimental workflow was illustrated in Fig. 5a, and surgical procedures were described as follows. Each rat was operated under general anesthesia with intraperitoneal administration of xylazine $(4 \mathrm{mg} / \mathrm{kg})$ and ketamine $(40 \mathrm{mg} / \mathrm{kg})$. A monolateral external fixator (Xinzhong, Tianjin, China) was mounted to fix the potential proximal and distal segments of the right tibia after exposure. Thereafter, a transverse osteotomy was performed at the midshaft of the tibia followed by suture. Each rat received local injection of serum-free DMEM, NG-CM, or MG-CM generated by $2 \times$ $10^{5}$ cells into the fracture area on days 3,5 , and 7 after surgery. The tibia specimens were harvested on week $2(n=10$ per group) and week 3 ( $n=5$ per group) after surgery.

\section{X-ray examination}

X-ray images of the fracture sites were acquired at the postoperative $4,7,10$, and 14 days under general anesthesia. A digital X-ray machine (Faxitron, Ultra Focus 100, Tucson, AZ, USA) was used with an exposure time of $6 \mathrm{~s}$ and a voltage of $32 \mathrm{kV}$. The radiographic images were scored as follows [27]: 1, no apparent hard callus; 2, slight intramembranous ossifification; 3 , hard callus without bridging of the fracture gap, fracture line is apparent; 4, hard callus with bridging of the fracture gap, fracture gap is noticeable; 5 , unclear boundary between the newly formed hard callus and existing cortical bone; and 6, remodeling. Evaluation was performed independently by three experienced orthopedic surgeons.

\section{Angiography}

To evaluate neovascularization of the fracture areas, cardiac Microfil (Flow Tech, Carver, MA, USA) perfusion of rats was performed under general anesthesia. The rats were placed at $4{ }^{\circ} \mathrm{C}$ for $24 \mathrm{~h}$ to ensure polymerization of the contrast agent. Thereafter, the tibia samples were harvested, fixed with $4 \%$ PFA at $4{ }^{\circ} \mathrm{C}$ for $24 \mathrm{~h}$, decalcified with ethylene diamine tetraacetic acid (EDTA; Solarbio) for 3 weeks and subjected to micro-computed tomography (micro-CT; Scanco Medical, Bassersdorf, Switzerland) scanning. The vessel volume of fracture areas was calculated and analyzed.

\section{Micro-CT analysis}

Ten rats in each group were sacrificed 2 weeks after surgery, and the structure within the fracture area was quantitatively assessed using the micro-CT $(15-\mu \mathrm{m}$ thickness per slide) with a voltage of $70 \mathrm{kV}$ and a current of $114 \mathrm{~mA}$. Three-dimensional bone structures were shown by sagittal images of the samples. Analysis for bone volume/total tissue volume (BV/TV) of fracture area of each specimen was performed.

\section{Four-point bending mechanical test}

The biomechanical parameters of the tibia samples were assessed using a four-point bending device (H25KS, Hounsfield Test Equipment, Surrey, UK). The tibia samples were loaded in the anterior-posterior direction at a loading rate of $5 \mathrm{~mm} / \mathrm{min}$ until failure. Stiffness, ultimate 
load, and energy to failure were analyzed by Vernier Graphical Analysis software.

\section{Histology and immunohistochemistry}

After fixation in $4 \%$ PFA for $24 \mathrm{~h}$, the tibia specimens were decalcified in 10\% EDTA for 4 weeks and embedded in paraffin. Tissue sections $(7-\mu \mathrm{m}$-thick) were sectioned along the sagittal plane for hematoxylin-eosin (H\&E) and Masson's trichrome staining. Immunohistochemistry staining was performed using primary antibodies against CD31 $(10 \mu \mathrm{g} / \mathrm{ml}, \mathrm{R} \& \mathrm{D}$, Minneapolis, MN, USA), VEGFA (Abcam, 1: 200), MMP-9 (Santa Cruz, 1: 50), and osteocalcin (OCN; Santa Cruz, 1: 50) overnight at $4{ }^{\circ} \mathrm{C}$. After incubation with secondary antibodies (Abcam, 1: 200) conjugated with horseradish peroxidase (HRP), a Dako REAL EnVision Detection System (Dako, Glostrup, Denmark) was used to detect positive areas followed by counterstaining with hematoxylin.

\section{Statistical analysis}

All data were presented as mean \pm standard deviation. Statistical analysis was performed with Student's $t$ test for two groups or one-way ANOVA followed by Turkey's post hoc test for comparison among multiple groups using SPSS 22.0 software (IBM, Armonk, NY), and a two-tailed $P$ value less than 0.05 was considered statistically significant.

\section{Results}

Characterization of human peripheral blood-derived EPCs After 7 days of culture, EPC-like colonies appeared and those cells within the colonies exhibited the typical cobblestone morphology of endothelial cells (Fig. 1a). The population of cells coexpressed a hematopoietic stem cell marker CD34 and endothelial markers CD31 and vWF, suggesting that these cells are endothelial and stem/progenitor lineage (Fig. 1b). In addition, biological and functional characterization demonstrated that the cells readily formed tube-like structures on seeding onto Matrigel (Fig. 1c), which is the feature of endothelial lineage cells. These results unequivocally confirmed that EPCs had been successfully isolated from the human peripheral blood.
MG attenuated EPCs' proliferation, but upregulated HIF$1 a /$ eNOS/NO signal

EPCs' proliferation cultured under MG was significantly suppressed compared to those under NG at the time points of $12 \mathrm{~h}, 24 \mathrm{~h}$, and $48 \mathrm{~h}$ (Fig. 2a), and the immunofluorescence results indicated that the 24-h MG exposure inhibited the expression of cell proliferation marker Ki67 (Fig. 2b). The qRT-PCR detection indicated the expression of angiogenic genes HIF- $1 \alpha$ and eNOS but VEGF, MMP-9, PDGF-B, and Ang-2 was significantly upregulated after 12- or 24-h exposure. However, the expression levels of HIF-1 $\alpha$ and eNOS decreased as the MG exposure time prolonged (Fig. 2c). The results at protein levels were consistent to the data at the mRNA level, and iNOS was not elicited by MG (Fig. 2d). Consequently, the NO abundance in CM modulated by MG was higher than that in control media at the time points of $12 \mathrm{~h}, 24 \mathrm{~h}$, and $48 \mathrm{~h}$ (Fig. 2e).

\section{MG-CM facilitated HUVECs' proliferation, migration, and angiogenesis in vitro}

The in vitro experiments were performed in HUVECs. As shown in Fig. 3a, b, MG-CM promoted the proliferation of HUVECs and the expression of Ki67 compared to NG-CM through increased NO. Consistently, the transwell assay and scratch assay confirmed that MG-CM facilitated the HUVECs' migration in a NOdependent manner (Fig. 3c-f), as well as CD31 expression (Fig. 3g). The matrigel tube formation assay was employed to detect the angiogenic capacities of HUVECs, and the results suggested that NO partially contributed to the enhanced angiogenic potential of MG-CM as revealed by total tube length (Fig. 3h, i). In addition, MG-CM also elevated the expression of angiogenic markers VEGF and MMP-9 in HUVECs (Fig. 3j).

The NO-induced activation of FAK/Erk1/2-MAPK signaling pathway contributed to the enhanced pro-angiogenic effects of MG-CM

To investigate the underlying mechanism of MG-CM promoting angiogenesis, the phosphorylation levels of
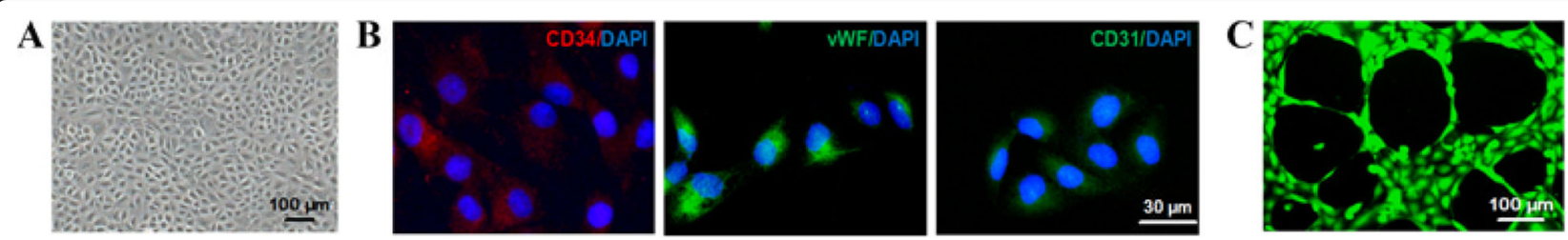

Fig. 1 Identification of human peripheral blood-derived EPCS. a The isolated human peripheral blood-derived EPCs exhibited the typical endothelial-like cobblestone morphology. b Immunofluorescence staining revealed that the cell population was positive for CD34 (left), vWF (middle) and CD31 (right). DAPI was for nuclear counterstain. c Tube-like structures were generated after EPCs were seeded onto matrigel-coated dish. This experiment was repeated independently three times. Abbreviations: EPCs, endothelial progenitor cells; DAPI, 4, 6-diamidino-2phenylindole; vWF, von Willebrand factor 


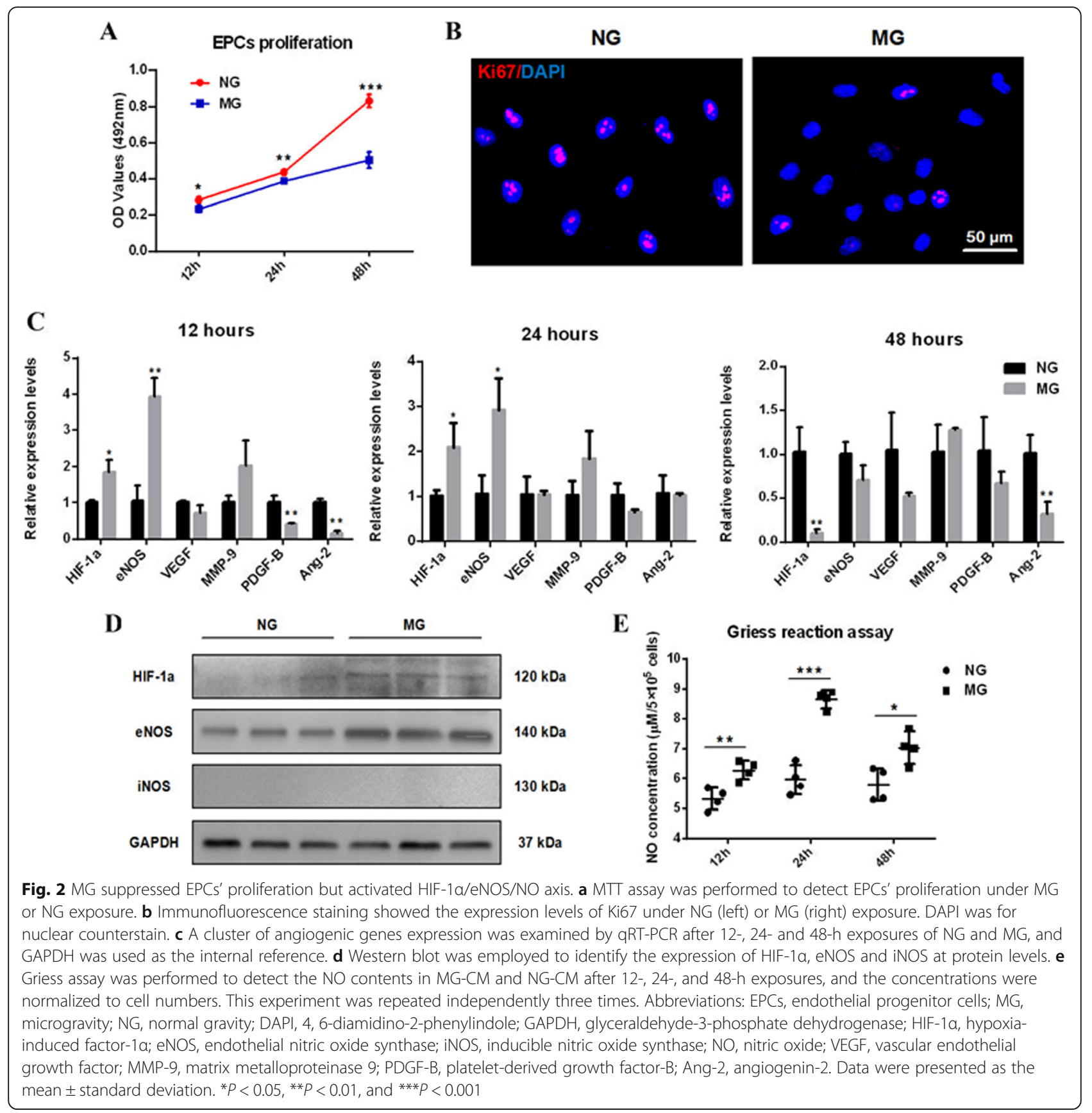

FAK and Erk1/2-MAPK were evaluated after 4-h treatment of MG-CM (Fig. 4a), and the activation of Erk1/2 could be eliminated by PD98059 (Fig. 4b), a specific inhibitor of Erk1/2-MAPK. Simultaneously, MG-CMmediated in vitro angiogenesis and Ki67 or CD31 upregulation were also compromised when the cells were pretreated with PD98059 (Fig. 4c-e), as well as the expression of angiogenic marker VEGF (Fig. 4f), suggesting the involvement of Erk1/2-MAPK in NO-induced angiogenesis in HUVECs (Fig. 4g).
MG-CM accelerated fracture healing and improved the mechanical properties of fracture bone in vivo

MG-CM was locally injected every other day for three times after surgery (Fig. 5a). No rat died or experienced evident complications during the experimental process. Representative tibia images of the fracture models at postoperative 4, 7, 10, and 14 days are shown in Fig. 5b. Radiographic score curves (Fig. 5c) based on these monitoring photographs revealed that both of NG-CM and MG-CM accelerated callus growth, and the latter was more prominent. 
A

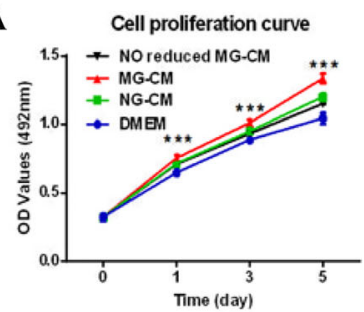

C

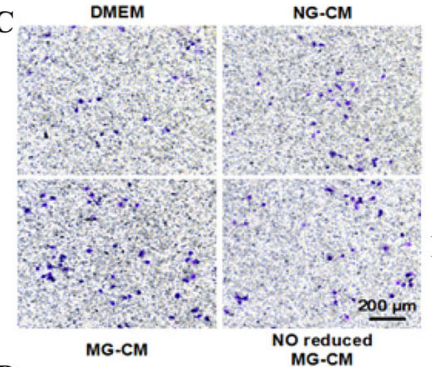

D

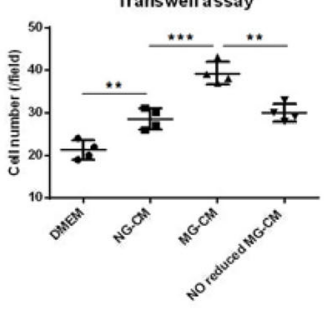

$\mathbf{F}$

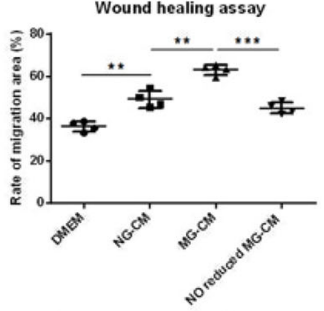

$\mathbf{H}$

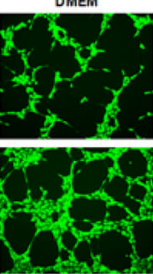

MG.CM

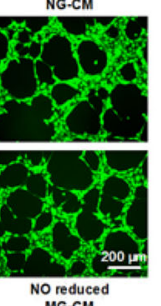

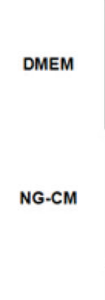

MG-CM
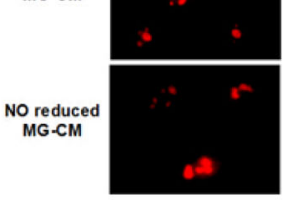

$\mathbf{E}$

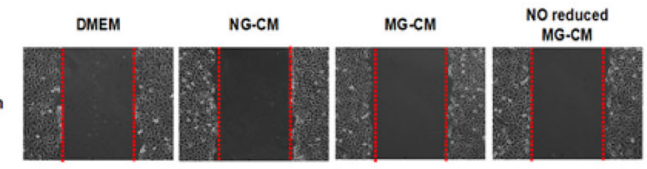

$12 \mathrm{~h}$

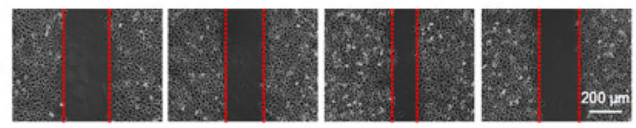

G
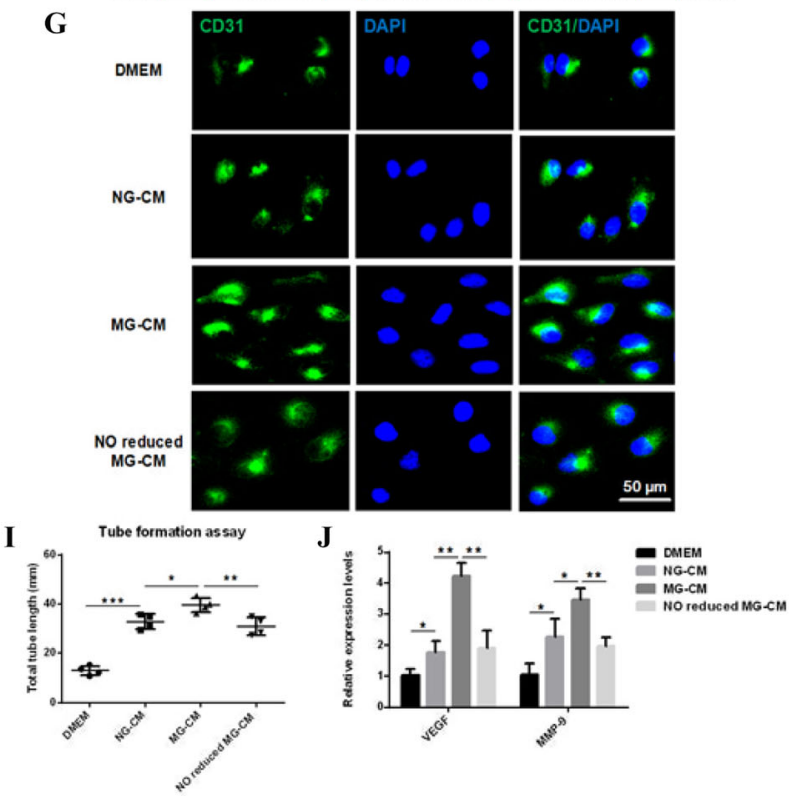

Fig. 3 MG-CM promoted HUVECs' proliferation, migration, and angiogenesis in vitro partially through increased NO production. a The effects of DMEM, NG-CM, MG-CM, and NO reduced MG-CM on HUVECs' proliferation were analyzed by MTT assay. $\mathbf{b}$ The Ki67 expression in HUVECs was detected by immunofluorescence staining. DAPI was for nuclear counterstain. c-f Transwell assay and wound healing assay were employed to detect the migration capacity changes of HUVECs after treatment followed by quantitative analyses. $\mathbf{g}$ The CD31 expression levels of HUVECs in each group were detected by immunofluorescence staining. $\mathbf{h}$, i Tube formation assay was used to detect the angiogenic abilities of HUVECs followed by quantitative analysis. $\mathbf{j}$ qRT-PCR results showed the relative expression levels of VEGF and MMP-9, with GAPDH as the internal reference. This experiment was repeated independently three times. Abbreviations: HUVECS, human umbilical vein endothelial cells; NG-CM, conditioned media from endothelial progenitor cells under normal gravity; MG-CM, conditioned media from endothelial progenitor cells under microgravity; NO, nitric oxide; DAPI, 4, 6-diamidino-2-phenylindole; GAPDH, glyceraldehyde-3-phosphate dehydrogenase; VEGF, vascular endothelial growth factor; MMP-9, matrix metalloproteinase 9. Data were presented as the mean \pm standard deviation. ${ }^{*} P<0.05$, ${ }^{*} P<0.01$, and ${ }^{* *} P<0.001$

The results of mechanical assessments were normalized to the contralateral intact tibia. The values of ultimate load, stiffness, and energy to failure indicated significant improvement of mechanical properties in the MG-CM and NG-CM groups comparing to the DMEM group, and MG-CM exerted the strongest effect (Fig. 5d), 


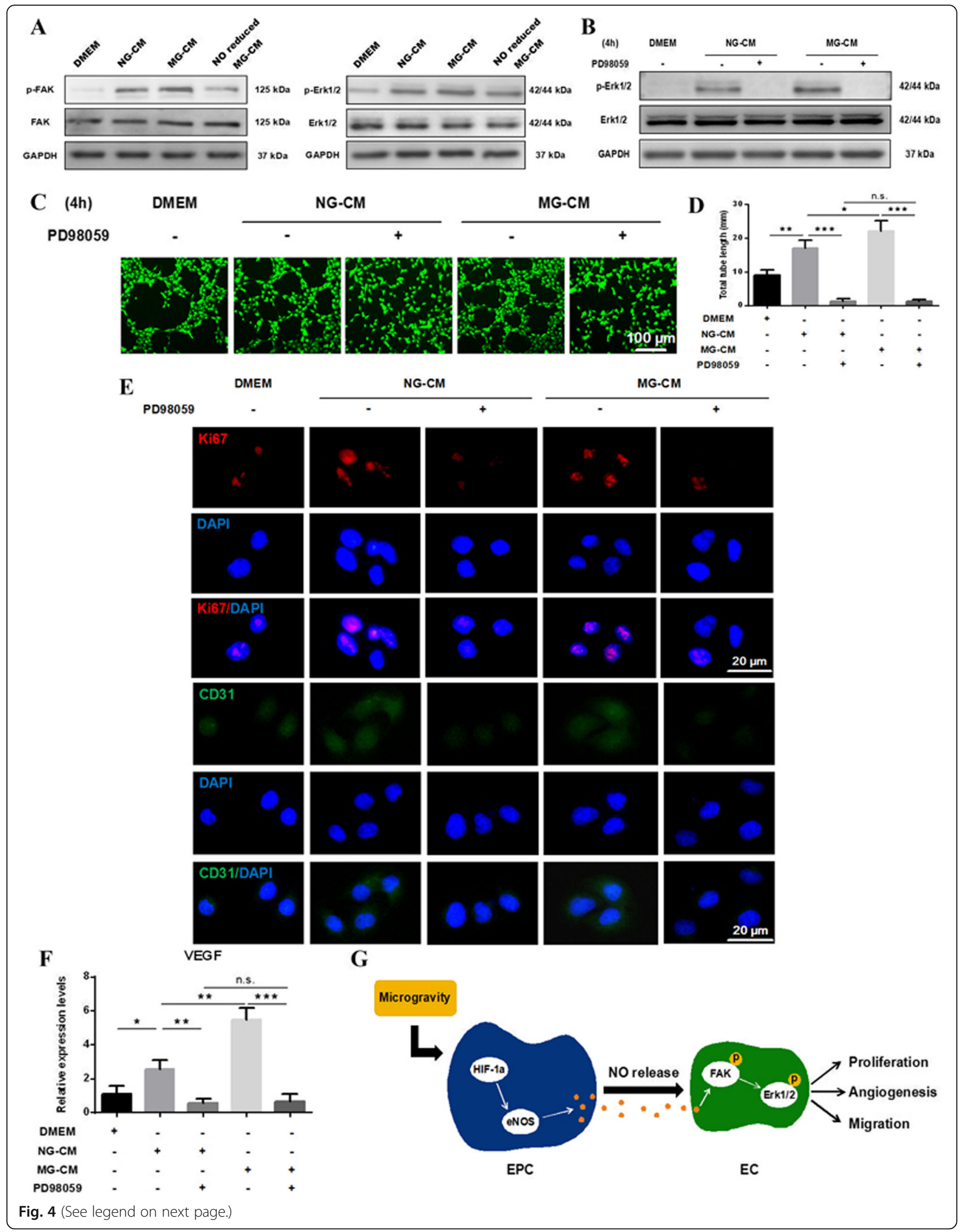


(See figure on previous page.)

Fig. 4 NO-induced activation of FAK/Erk1/2-MAPK signaling pathway contributed to enhanced pro-angiogenic properties of MG-CM. a Western blot was employed to detect the phosphorylation levels of FAK and Erk1/2. b The phosphorylation level of Erk1/2 was examined after Erk1/2MAPK-selective inhibitor PD98059 application for 4 h. c, $\mathbf{d}$ Tube formation assay was performed to detect the angiogenic abilities of HUVECs when PD98059 was added or not, followed by quantitative analysis. e Immunofluorescence staining results showed the expression of Ki67 and CD31 in different groups. DAPI was for nuclear counterstain. $\mathbf{f}$ The mRNA expression level of VEGF was detected by qRT-PCR, and GAPDH was used as internal reference. $\mathbf{g}$ The schematic illustration of MG-induced HIF-1a/eNOS/NO activation of EPCs promoting HUVECs' proliferation, migration, and angiogenesis. This experiment was repeated independently three times. Abbreviations: EPCs, endothelial progenitor cells; HUVECs, human umbilical vein endothelial cells; FAK, focal adhesion kinase; NG-CM, conditioned media from endothelial progenitor cells under normal gravity; MG-CM, conditioned media from endothelial progenitor cells under microgravity; NO, nitric oxide; DAPI, 4, 6-diamidino-2-phenylindole; GAPDH, glyceraldehyde-3-phosphate dehydrogenase; VEGF, vascular endothelial growth factor; HIF-1a, hypoxia-induced factor-1a; eNOS, endothelial nitric oxide synthase. Data were presented as the mean \pm standard deviation. ${ }^{*} P<0.05,{ }^{* *} P<0.01$, and ${ }^{* * *} P<0.001$

suggesting a better biomechanical recovery of the suffered bone induced by MG-CM.

\section{MG-CM promoted neovascularization of fracture area in vivo} The results of micro-CT-based angiography demonstrated that rats with repeated injection of MG-CM exhibited more capillaries and total vessel volume when compared with DMEM and NG-CM groups (Fig. 6a, b). Immunohistochemistry staining for CD31 was performed to detect mature vessels, and VEGF-A and MMP-9 detection was employed to observe angiogenic activities. As shown in Fig. 6c-h, more CD31-positive vessels and active angiogenesis in the new bone zone in the MG-CM group than the other two groups, suggesting improved angiogenesis in fracture sites induced by MG-CM in a rat fracture model.

\section{MG-CM promoted fracture repair in vivo}

Bone regeneration was quantified via micro-CT at 2 weeks after surgery. Sagittal planes of 3D reconstruction images of surgical tibia are shown in Fig. 7a, and the $\mathrm{BV} / \mathrm{TV}$ values were significantly higher in the MG-CM
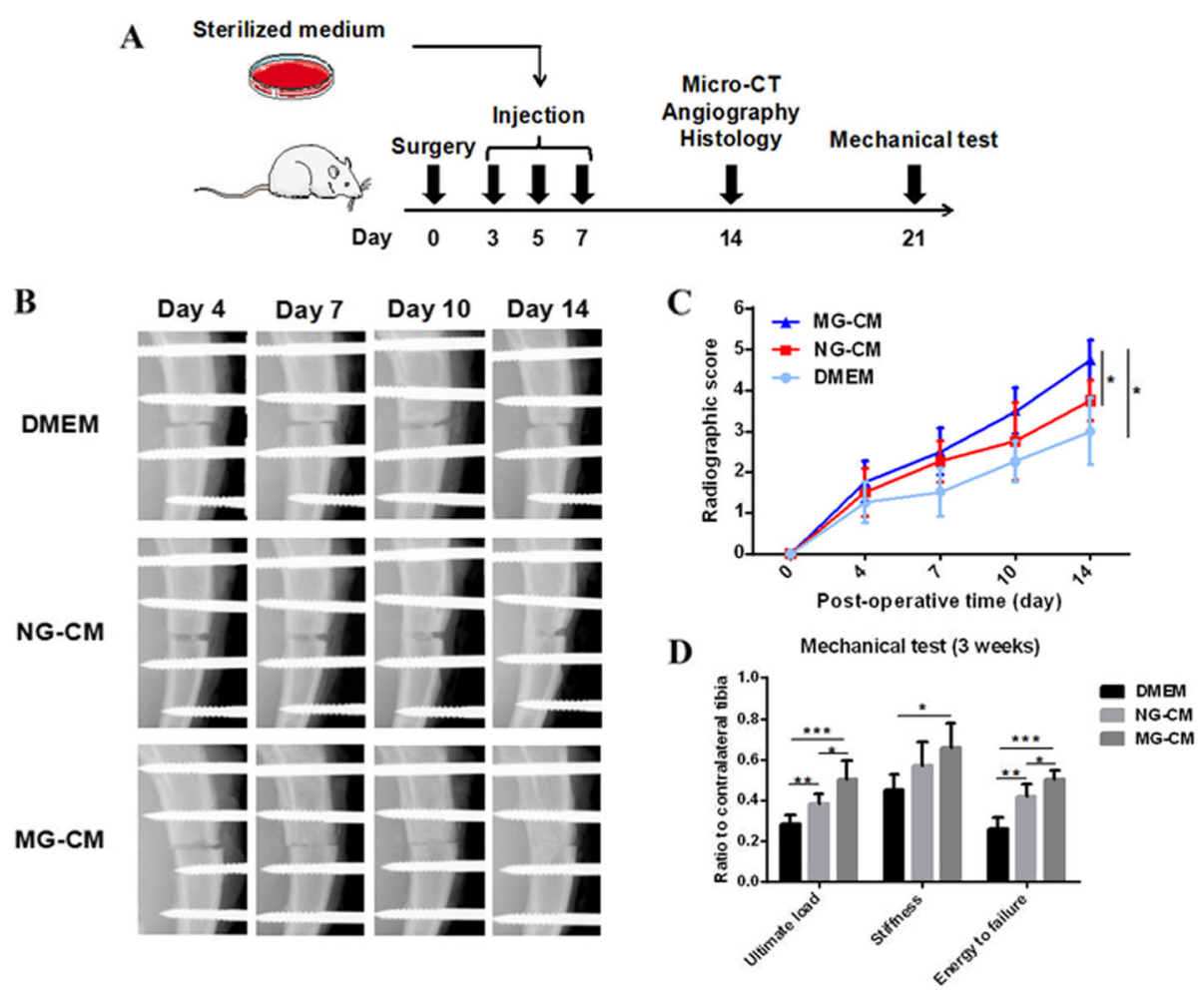

Fig. 5 MG-CM accelerated callus growth and improved mechanical properties of fracture bone. a The workflow of animal experiments, including surgery, interventions, and detection. $\mathbf{b}$ The representative X-ray images of the regenerates in DMEM, NG-CM and MG-CM groups at 4, 7, 10, and 14 days after surgery. $\mathbf{c}$ The callus growth of rats was quantified by radiological scores. $\mathbf{d}$ Mechanical properties of fracture bone including ultimate load, stiffness, and energy to failure were evaluated at postoperative 3 weeks. Abbreviations: NG-CM, conditioned media from endothelial progenitor cells under normal gravity; MG-CM, conditioned media from endothelial progenitor cells under microgravity. Data were presented as the mean \pm standard deviation. ${ }^{*} P<0.05,{ }^{*} P<0.01$, and ${ }^{* * *} P<0.001$ 


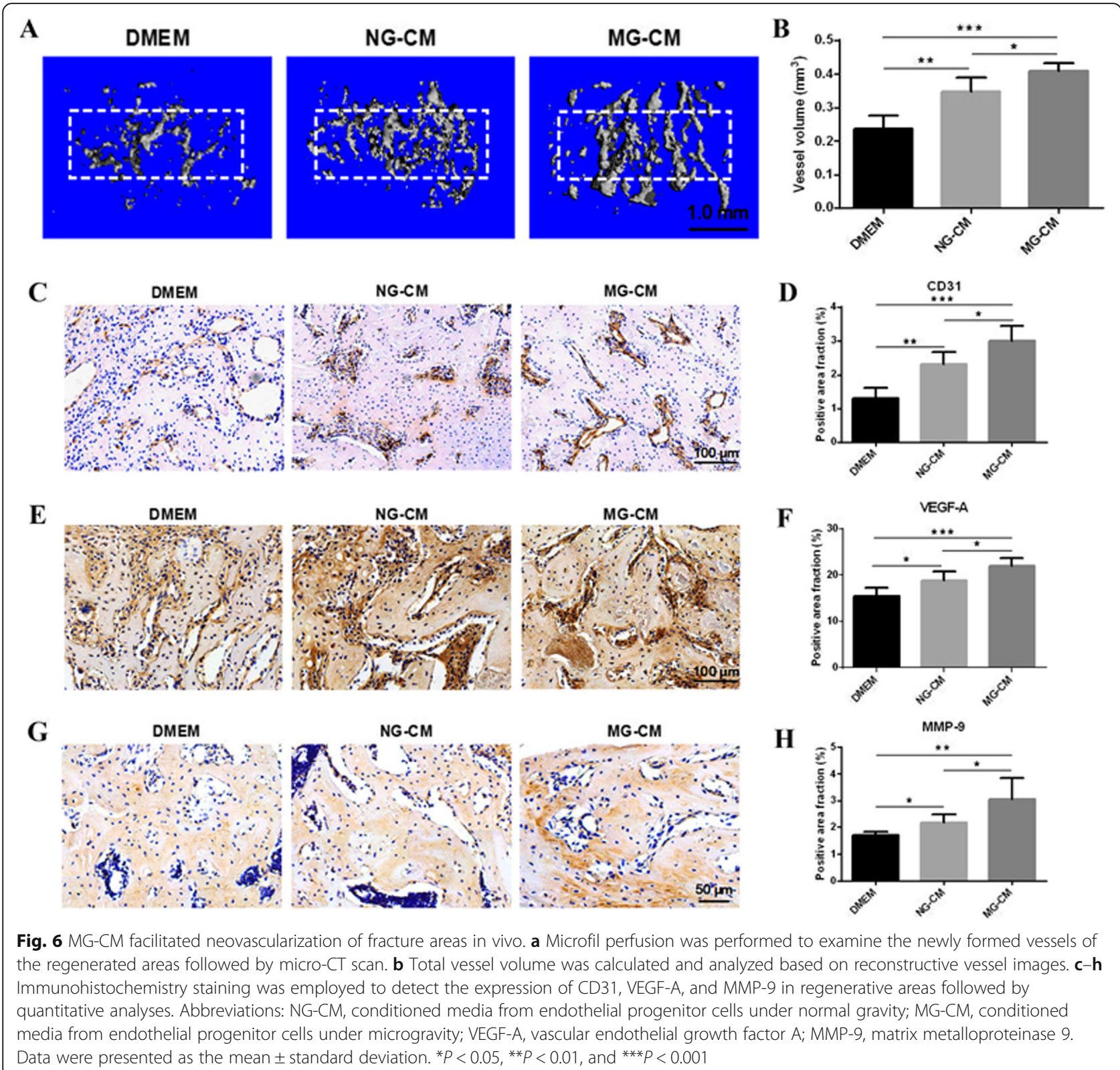

group than in the DMEM and NG-CM groups (Fig. 7b), suggesting the beneficial effects of MG-CM in promoting bone regeneration. H\&E and Masson's trichrome staining of the fracture bone treated with MG-CM exhibited solid bone structure at postoperative 2 weeks in comparison with the DMEM and NG-CM groups (Fig. 7c). In DMEM-treated samples, the fracture area contained more fibrous and cartilaginous tissues and less trabecular bone near the cortical bone. Upon treatment of NG-CM or MG-CM, the fracture area displayed more mature trabecular bone tissues, and part of the callus in MG-CM group was in the process of remodeling. The OCN immunostaining showed that MG-CM application led to enhanced osteogenesis compared to control (Fig. 7d, e).

\section{Discussion}

In this study, we found that MG activated the HIF-1 $\alpha$ / eNOS axis and increased NO production. Although both of NG-CM and MG-CM enhanced the angiogenic capacities of endothelial cells in vitro, the MG-CM exhibited more robust potentials via NO-induced activation of FAK/Erk1/2-MAPK signaling pathway. Moreover, repeatedly local administration of MG-CM promoted neovascularization, accelerated fracture healing and improved the mechanical properties of fracture bone superior to NG-CM in a rat fracture model.

Previous studies reported that MG is a risk factor hampering cardiovascular system and the functions of endothelial cells and EPCs are regulated by gravity 


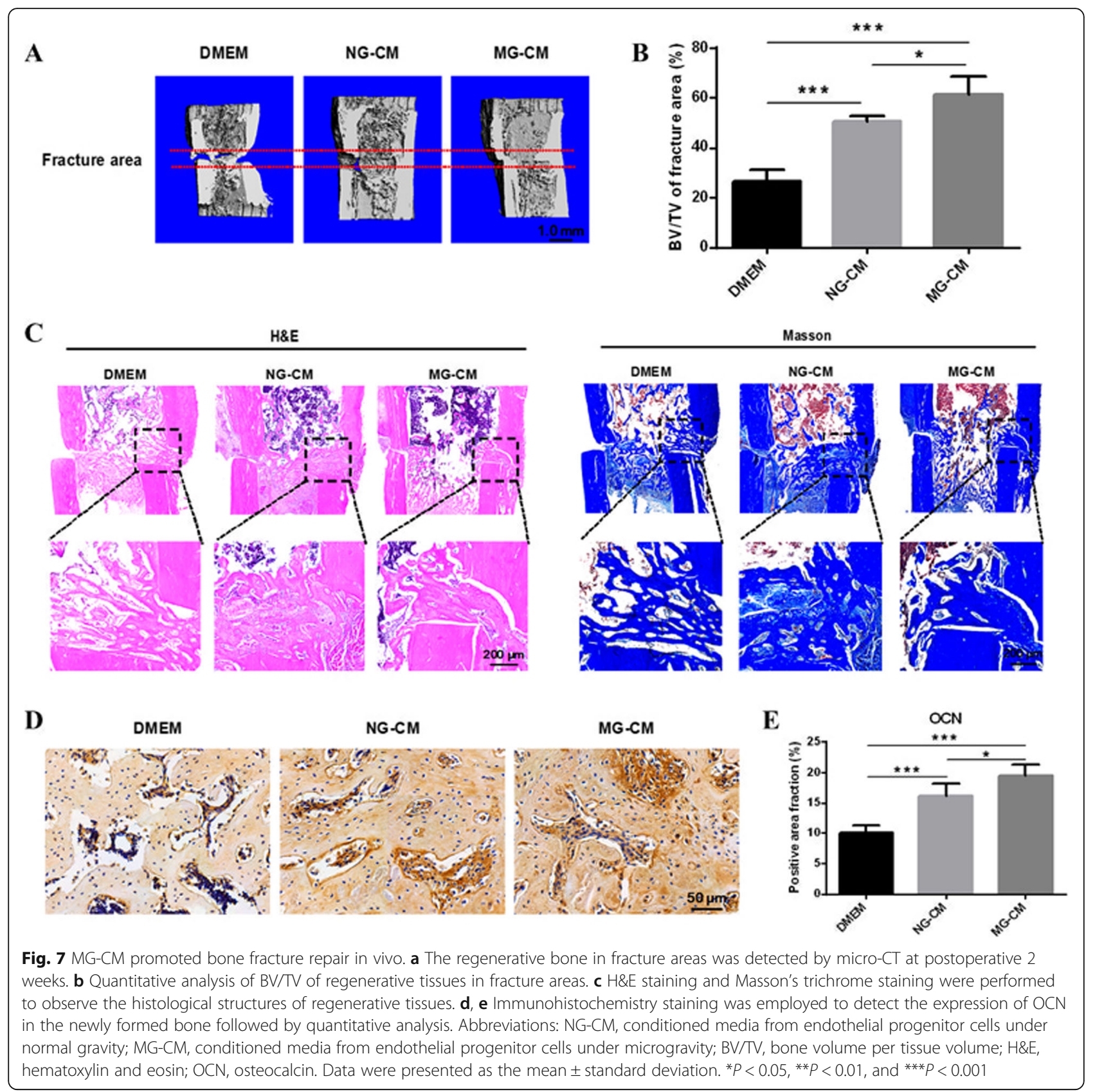

variations $[28,29]$. Furthermore, MG alters the expression levels of microRNAs and mRNAs; those regulate mechnotransduction signals, cell migration, angiogenesis and osteogenic differentiation in cardiovascular progenitor cells [24]. Ramaswamy et al. [22] have reported that simulated MG inhibits proliferation, migration, and differentiation of the porcine blood-derived vascular stem cells, but prolonged MG exposure (more than $12 \mathrm{~h}$ ) may restore the angiogenic capacities of this cell population. Consistently, the present study also showed that shortterm MG exposure significantly attenuated the proliferation of EPCs. However, it is also reported that MG exposure followed by NG culture could improve EPCs' expansion rates and paracrine properties [25]. Therefore, MG simulation may be a powerful bioengineering tool for eliciting cell angiogenic potentials. Previously, altered gravity was identified to regulate oxygen homeostasis and HIF-1-dependent transcripts [30, 31], and consequently refine the regenerative potentials of cells similar to hypoxic culture [32]. In our study, we for the first time found the HIF-1 $\alpha /$ eNOS axis was activated by MG within $24 \mathrm{~h}$, partially supporting the previous findings and complementing them [22, 24, 25]. As eNOS-derived $\mathrm{NO}$ are mainly regulated by angiogenic effectors or 
mechanical stress, which are responsible for vascular function maintenance, while iNOS induced NO are by proinflammatory cytokines that are usually involved in vascular pathologic processes [33, 34]. NO production in the current study was accompanied with eNOS upregulation rather than iNOS; we therefore considered that HIF- $1 \alpha /$ eNOS axis activation mainly contributed to increased NO release. These results initially revealed the changes of NO release and its upstream signals in EPCs upon to short-term MG stimulation.

EPCs are required for neovascularization and tissue regeneration during bone fracture healing and other injury repairs [35, 36]. Furthermore, the secretomes derived from EPCs in CM such as exosomes have been demonstrated to protect endothelial function and induce angiogenesis in spinal cord injury and distraction osteogenesis $[12,37]$. Exosomes derived from EPCs, as an important paracrine nanocarriers in $\mathrm{CM}$, could exert the proangiogenic effects of EPCs by transferring RNAs, proteins, and lipids whereas avoiding the possible complications of cell transplantation including emboli formation, immunogenicity, and malignant transformation. In this study, exosomes indeed contributed to the proangiogenic effects of $\mathrm{CM}$, and $\mathrm{NO}$ might also be stored in both media solution and exosomes. Since short-term MG stimulation tends to improve the paracrine properties of EPCs, we therefore evaluated the effects of MG$\mathrm{CM}$ of EPCs on angiogenesis in vitro and bone fracture healing in vivo. As we hypothesized, MG-CM enhanced HUVECs' proliferation, migration, and matrigel angiogenesis capacities, also indicated by the expression alterations of proliferation marker Ki67 and angiogenic markers CD31, VEGF, and MMP-9, while these enhanced effects were weakened to a certain extent in the presence of NO scavenger carboxy-PTIO, suggesting $\mathrm{NO}$ contributed, at least in part, to more robust angiogenic properties of MG-CM. Our results and previous reports $[38,39]$ together emphasized the pro-angiogenic effects of endogenous NO served as an active paracrine factors. In vivo, the total vessel volume and CD31 positive vessels in the regenerated areas increased after MG$\mathrm{CM}$ injection as shown by angiography and histological detection, VEGF and MMP-9 expression as well. As illustrated by in vitro and in vivo data, MG-CM exhibited better pro-angiogenic capacities, which indicated that MG elicited robust angiogenic potentials of EPCs.

In terms of pro-angiogenic mechanisms, eNOSderived NO as a well-acknowledged angiogenic gasotransmitter regulates several key signaling pathways in cardiovascular health maintenance, including Akt-PI3K and MAPK $[16,39,40]$. Although NO is a type of gasotransmitter, it mainly exists in CM in the form of nitrite, which is adequately stable and reversibly converted into NO to function. These biochemical properties provide a reliable prerequisite for $\mathrm{NO}$ to effectively activate downstream signals. FAK, a membrane-proximal tyrosine kinase, was reported to transfer NO signals to downstream Erk1/2 to promote cell survival, migration, and angiogenesis [41-44]. In this study, we also found endogenous $\mathrm{NO}$ in CM significantly improved endothelial cells' proliferation, migration, and angiogenesis through stimulating tyrosine phosphorylation of FAK and its downstream Erk1/2-MAPK, while the selective inhibitor PD98059 of this pathway remarkably impaired the FAK/Erk1/2MAPK signal transduction and pro-angiogenic effects of MG-CM. These findings suggested that $\mathrm{NO}$ as a crucial paracrine signal of EPCs under MG improved angiogenic capacities of endothelial cells totally or partially through FAK/Erk1/2-MAPK signaling pathway (Fig. 4g).

Neovascularization is prerequisite for the sufficient blood supply, which maintains growth of regenerative callus [45]. In our study, repeated administration of MG-CM enriched vascular network, significantly accelerating callus formation as shown by X-ray imaging and enhancing the osteogenic activities in the regenerated areas as revealed by micro-CT analyses and histological detection. In addition, mechanical properties of fracture tibia were improved in the MG-CM group comparing to the control and NG-CM groups. Therefore, the fact that robust pro-angiogenic properties of MG-CM facilitated fracture repair in this study reflected the tight couple between angiogenesis and osteogenesis although the possibility could not be excluded that MG-CM directly improved osteogenic activities. Recently, accumulating evidence [12, 46, 47] suggested that the applications of exosomes, CM, and secretome were benefit to bone regeneration, and we demonstrated that MG could further improve the fracture repair properties of CM from EPCs whereas avoiding the possible complications of cell transplantation. These findings pointed that EPCsderived CM after MG modulation may be another useful therapeutic approach for nonunion or delayed union.

There were still limitations to this study. First, despite activation of HIF- $1 \alpha / \mathrm{eNOS} / \mathrm{NO}$, other angiogenic factors may also contribute to MG-induced enhanced angiogenic properties. Our future studies will search for additional MG-modulated angiogenic genes with proteomics and functional approaches. Second, it was reported that space flight may lead to cardiovascular harm and bone mass loss $[29,48]$, which seems to be contradictory with our findings in this study. Although it could be explained by distinct MG exposure duration and complicated in vivo environment, future work will be designed to fully elucidate it.

\section{Conclusion}

The present study demonstrated that MG-induced HIF$1 \alpha /$ eNOS activation and increased NO production 
partially contributed to enhanced angiogenic properties of EPC-derived CM through FAK/Erk1/2-MAPK pathway, indicating MG tends to act as a useful bioreactor to improve paracrine angiogenic potentials of EPCs. In vivo, the local application of MG-CM promoted neovascularization and fracture healing, providing a novel bone regenerative strategy for nonunion and delayed union. Future studies are required to deep explore full-scale EPCs responses to MG and evaluate the efficacy of MG$\mathrm{CM}$ in other disease models.

\section{Supplementary information}

The online version contains supplementary material available at https://doi. org/10.1186/s13287-020-02074-y.

Additional file 1. Supplementary Table 1

\section{Abbreviations}

EPCS: Endothelial progenitor cells; MG: Microgravity; NG: Normal gravity; CM: Conditioned media; HIF-1a: Hypoxia-induced factor-1a;

eNOS: Endothelial nitric oxide synthase; iNOS: Inducible nitric oxide synthase; HUVECS: Human umbilical vein endothelial cells; vWF: Von willebrand factor; VEGF: Vascular endothelial growth factor; MMP-9: Matrix metalloproteinase-9; PDGF-B: Platelet-derived growth factor-B; Ang-2: Angiogenin-2;

OCN: Osteocalcin; GAPDH: Glyceraldehyde-3-phosphate dehydrogenase; FAK: Focal adhesion kinase; Micro-CT: Micro-computed tomography; BV/ TV: Bone volume/total tissue volume; H\&E: Hematoxylin-eosin

\section{Acknowledgements}

We appreciate supports from the SMART program, Lui Che Woo Institute of Innovative Medicine, The Chinese University of Hong Kong.

\section{Authors' contributions}

Kong L, Wang Y, Wang H, Pan Q, Zuo R, Bai S, Zhang X: experimental planning, doing the experiments, data collection, data analysis and paper drafting. Lee WY, Kang Q and Li G: experimental design, provide funding, paper editing and proof reading. The authors read and approved the final manuscript.

\section{Funding}

This work was supported partially by the National Natural Science Foundation of China (grant numbers 82072421, 81772322, and 81572121); Hong Kong Government Research Grant Council, General Research Fund (14120118, 14160917, C7030-18G and T13-402/17-N); Hong Kong Innovation Technology Commission Funds (PRP/050/19FX); and Hong Kong Medical Research Funds (16170951 and 17180831).

\section{Availability of data and materials}

All data generated or analyzed during this study are included in this published article.

\section{Ethics approval and consent to participate}

All the human cell experiments and animal procedures were performed in full compliance with the institutional guidelines and were approved by the Ethics Committees of Shanghai Jiao Tong University Affiliated Sixth People's Hospital.

\section{Consent for publication}

Not applicable.

\section{Competing interests}

The authors declare that they have no competing interests.

\section{Author details}

'Department of Orthopaedic Surgery, Shanghai Jiao Tong University Affiliated Sixth People's Hospital, Yishan Rd. 600, Shanghai 200233, People's
Republic of China. ${ }^{2}$ Department of Orthopaedics \& Traumatology, Stem Cells and Regenerative Medicine Laboratory, Li Ka Shing Institute of Health Sciences, Faculty of Medicine, The Chinese University of Hong Kong, Prince of Wales Hospital, Shatin, Hong Kong SAR PRC. ${ }^{3}$ The CUHK-ACC Space Medicine Centre on Health Maintenance of Musculoskeletal System, The Chinese University of Hong Kong Shenzhen Research Institute, Shenzhen, People's Republic of China. ${ }^{4}$ Key Laboratory for Regenerative Medicine, Ministry of Education, School of Biomedical Sciences, Faculty of Medicine, The Chinese University of Hong Kong, Shatin, Hong Kong SAR PRC.

Received: 10 November 2020 Accepted: 6 December 2020 Published online: 08 January 2021

\section{References}

1. Einhorn TA, Gerstenfeld LC. Fracture healing: mechanisms and interventions. Nat Rev Rheumatol. 2015;11:45-54

2. Antonova $E$, Le TK, Burge R, Mershon J. Tibia shaft fractures: costly burden of nonunions. BMC Musculoskelet Disord. 2013:14:42.

3. Ding ZC, Lin YK, Gan YK, Tang TT. Molecular pathogenesis of fracture nonunion. J Orthop Translat. 2018;14:45-56.

4. Filipowska J, Tomaszewski KA, Niedzwiedzki L, Walocha JA, Niedzwiedzki T. The role of vasculature in bone development, regeneration and proper systemic functioning. Angiogenesis. 2017;20:291-302.

5. Asahara T, Murohara T, Sullivan A, Silver M, van der Zee R, Li T, Witzenbichler B, Schatteman G, Isner JM. Isolation of putative progenitor endothelial cells for angiogenesis. Science. 1997;275:964-7.

6. Ishikawa M, Asahara T. Endothelial progenitor cell culture for vascular regeneration. Stem Cells Dev. 2004;13:344-9.

7. Kim JY, Song SH, Kim KL, Ko JJ, Im JE, Yie SW, Ahn YK, Kim DK, Suh W. Human cord blood-derived endothelial progenitor cells and their conditioned media exhibit therapeutic equivalence for diabetic wound healing. Cell Transplant. 2010;19:1635-44.

8. Fang J, Guo Y, Tan S, Li Z, Xie H, Chen P, Wang K, He Z, He P, Ke Y, Jiang X, Chen Z. Autologous endothelial progenitor cells transplantation for acute ischemic stroke: a 4-year follow-up study. Stem Cells Transl Med. 2019:8:14-21.

9. Lopes L, Setia O, Aurshina A, Liu S, Hu H, Isaji T, Liu H, Wang T, Ono S, Guo X, Yatsula B, Guo J, Gu Y, Navarro T, Dardik A. Stem cell therapy for diabetic foot ulcers: a review of preclinical and clinical research. Stem Cell Res Ther. 2018;9:188.

10. Rozen N, Bick T, Bajayo A, Shamian B, Schrift-Tzadok M, Gabet Y, Yayon A, Bab I, Soudry M, Lewinson D. Transplanted blood-derived endothelial progenitor cells (EPC) enhance bridging of sheep tibia critical size defects. Bone. 2009;45:918-24.

11. Herberts CA, Kwa MS, Hermsen HP. Risk factors in the development of stem cell therapy. J Transl Med. 2011;9:29.

12. Jia Y, Zhu Y, Qiu S, Xu J, Chai Y. Exosomes secreted by endothelial progenitor cells accelerate bone regeneration during distraction osteogenesis by stimulating angiogenesis. Stem Cell Res Ther. 2019;10:12.

13. Di Santo S, Fuchs AL, Periasamy R, Seiler S, Widmer HR. The cytoprotective effects of human endothelial progenitor cell-conditioned medium against an ischemic insult are not dependent on VEGF and IL-8. Cell Transplant. 2016:25:735-47.

14. Di Santo S, Yang Z, Wyler von Ballmoos M, Voelzmann J, Diehm N, Baumgartner I, Kalka C. Novel cell-free strategy for therapeutic angiogenesis: in vitro generated conditioned medium can replace progenitor cell transplantation PLoS One 2009:4: e5643.

15. Duda DG, Fukumura D, Jain RK. Role of eNOS in neovascularization: NO for endothelial progenitor cells. Trends Mol Med. 2004;10:143-5.

16. Ghimire K, Altmann HM, Straub AC, Isenberg JS. Nitric oxide: what's new to NO? Am J Physiol Cell Physiol. 2017;312:C254-62.

17. Priya MK, Sahu G, Soto-Pantoja DR, Goldy N, Sundaresan AM, Jadhav V, Barathkumar TR, Saran U, Jaffar Ali BM, Roberts DD, Bera AK, Chatterjee S. Tipping off endothelial tubes: nitric oxide drives tip cells. Angiogenesis. 2015;18:175-89.

18. Shi Y, Lv X, Liu Y, Li B, Liu M, Yan M, Liu Y, Li Q, Zhang X, He S, Zhu M, He J, Zhu Y, Zhu Y, Ai D. Elevating ATP-binding cassette transporter G1 improves re-endothelialization function of endothelial progenitor cells via Lyn/Akt/ eNOS in diabetic mice. FASEB J. 2018;32:6525-36.

19. Wu JR, Hsu JH, Dai ZK, Wu BN, Chen IJ, Liou SF, Yeh JL. Activation of endothelial NO synthase by a xanthine derivative ameliorates hypoxia- 
induced apoptosis in endothelial progenitor cells. J Pharm Pharmacol. 2016; 68:810-8.

20. Imura T, Nakagawa K, Kawahara Y, Yuge L. Stem cell culture in microgravity and its application in cell-based therapy. Stem Cells Dev. 2018;27:1298-302.

21. Kurose T, Takahashi S, Otsuka T, Nakagawa K, Imura T, Sueda T, Yuge L. Simulated microgravity-cultured mesenchymal stem cells improve recovery following spinal cord ischemia in rats. Stem Cell Res. 2019;41:101601.

22. Ramaswamy $\mathrm{V}$, Dirr EW, Allen JB. The effect of simulated microgravity on differentiation of porcine blood-derived vascular stem cells. Stem Cells Dev. 2016:25:329-36.

23. Hughson RL, Helm A, Durante M. Heart in space: effect of the extraterrestrial environment on the cardiovascular system. Nat Rev Cardiol. 2018;15:167-80.

24. Baio J, Martinez AF, Silva I, Hoehn CV, Countryman S, Bailey L, Hasaniya N, Pecaut MJ, Kearns-Jonker M. Cardiovascular progenitor cells cultured aboard the International Space Station exhibit altered developmental and functional properties. NPJ Microgravity. 2018;4:13.

25. Hagiwara H, Higashibata A, Ogawa S, Kanazawa S, Mizuno H, Tanaka R. Effectiveness of endothelial progenitor cell culture under microgravity for improved angiogenic potential. Sci Rep. 2018:8:14239.

26. Emontzpohl C, Simons D, Kraemer S, Goetzenich A, Marx G, Bernhagen J, Stoppe C. Isolation of endothelial progenitor cells from healthy volunteers and their migratory potential influenced by serum samples after cardiac surgery. J Vis Exp. 2017;4(120):55192.

27. Murata K, Ito H, Yoshitomi H, Yamamoto K, Fukuda A, Yoshikawa J, Furu M, Ishikawa M, Shibuya H, Matsuda S. Inhibition of miR-92a enhances fracture healing via promoting angiogenesis in a model of stabilized fracture in young mice. J Bone Miner Res. 2014;29:316-26.

28. Griffoni C, Di Molfetta S, Fantozzi L, Zanetti C, Pippia P, Tomasi V, Spisni E. Modification of proteins secreted by endothelial cells during modeled low gravity exposure. J Cell Biochem. 2011;112:265-72.

29. Versari S, Longinotti G, Barenghi L, Maier JA, Bradamante S. The challenging environment on board the International Space Station affects endothelial cell function by triggering oxidative stress through thioredoxin interacting protein overexpression: the ESA-SPHINX experiment. FASEB J. 2013;27:446675 .

30. Wang T, Chen H, Lv K, Ji G, Liang F, Zhang Y, Wang Y, Liu X, Cao H, Kan G, Xiong J, Li Y, Qu L. Activation of HIF-1alpha and its downstream targets in rat hippocampus after long-term simulated microgravity exposure. Biochem Biophys Res Commun. 2017:485:591-7.

31. Vogel J, Thiel CS, Tauber S, Stockmann C, Gassmann M, Ullrich O. Expression of hypoxia-inducible factor 1alpha (HIF-1alpha) and genes of related pathways in altered gravity. Int J Mol Sci 2019;20(2):436.

32. Liu W, Li L, Rong Y, Qian D, Chen J, Zhou Z, Luo Y, Jiang D, Cheng L, Zhao S, Kong F, Wang J, Zhou Z, XU T, Gong F, Huang Y, Gu C, Zhao X, Bai J, Wang F, Zhao W, Zhang L, Li X, Yin G, Fan J, Cai W. Hypoxic mesenchymal stem cell-derived exosomes promote bone fracture healing by the transfer of miR-126. Acta Biomater. 2020;103:196-212.

33. Forstermann U, Sessa WC. Nitric oxide synthases: regulation and function. Eur Heart J. 2012;33:829-37 837a-837d.

34. Kamel NM, Abd El Fattah MA, El-Abhar HS, Abdallah DM. Novel repair mechanisms in a renal ischaemia/reperfusion model: subsequent saxagliptin treatment modulates the pro-angiogenic GLP-1/CAMPNEGF, ANP/eNOS/NO, SDF-1alpha/CXCR4, and Kim-1/STAT3/HIF-1alpha/NEGF/eNOS pathways. Eur J Pharmacol. 2019:861:172620.

35. Liu H, Jiao Y, Zhou W, Bai S, Feng Z, Dong Y, Liu Q, Feng X, Zhao Y. Endothelial progenitor cells improve the therapeutic effect of mesenchymal stem cell sheets on irradiated bone defect repair in a rat model. J Trans! Med. 2018;16:137.

36. Peters EB. Endothelial progenitor cells for the vascularization of engineered tissues. Tissue Eng Part B Rev. 2018;24:1-24.

37. Wang $T$, Fang $X$, Yin ZS. Endothelial progenitor cell-conditioned medium promotes angiogenesis and is neuroprotective after spinal cord injury. Neural Regen Res. 2018;13:887-95.

38. Lee CZ, Xue Z, Hao Q, Yang GY, Young WL. Nitric oxide in vascular endothelial growth factor-induced focal angiogenesis and matrix metalloproteinase-9 activity in the mouse brain. Stroke. 2009;40:2879-81

39. Bettaga N, Jager R, Dunnes S, Groneberg D, Friebe A. Cell-specific impact of nitric oxide-dependent guanylyl cyclase on arteriogenesis and angiogenesis in mice. Angiogenesis. 2015;18:245-54.

40. Kasuno K, Takabuchi S, Fukuda K, Kizaka-Kondoh S, Yodoi J, Adachi T, Semenza GL, Hirota K. Nitric oxide induces hypoxia-inducible factor 1 activation that is dependent on MAPK and phosphatidylinositol 3-kinase signaling. J Biol Chem. 2004;279:2550-8.

41. Zhao X, Guan JL. Focal adhesion kinase and its signaling pathways in cell migration and angiogenesis. Adv Drug Deliv Rev. 2011;63:610-5.

42. Monteiro HP, Gruia-Gray J, Peranovich TM, de Oliveira LC, Stern A. Nitric oxide stimulates tyrosine phosphorylation of focal adhesion kinase, Src kinase, and mitogen-activated protein kinases in murine fibroblasts. Free Radic Biol Med. 2000;28:174-82.

43. Garcia-Benito M, San Roman JI, Lopez MA, Garcia-Marin LJ, Calvo JJ. Nitric oxide stimulates tyrosine phosphorylation of p125(FAK) and paxillin in rat pancreatic acini. Biochem Biophys Res Commun. 2000;274:635-40.

44. Rhoads JM, Chen W, Gookin J, Wu GY, Fu Q, Blikslager AT, Rippe RA, Argenzio RA, Cance WG, Weaver EM, Romer LH. Arginine stimulates intestinal cell migration through a focal adhesion kinase dependent mechanism. Gut. 2004;53:514-22.

45. Brandi ML, Collin-Osdoby P. Vascular biology and the skeleton. J Bone Miner Res. 2006;21:183-92.

46. Furuta T, Miyaki S, Ishitobi H, Ogura T, Kato Y, Kamei N, Miyado K, Higashi Y, Ochi M. Mesenchymal stem cell-derived exosomes promote fracture healing in a mouse model. Stem Cells Transl Med. 2016;5:1620-30.

47. Xu J, Wang B, Sun Y, Wu T, Liu Y, Zhang J, Lee WY, Pan X, Chai Y, Li G. Human fetal mesenchymal stem cell secretome enhances bone consolidation in distraction osteogenesis. Stem Cell Res Ther. 2016;7:134

48. Grimm D, Grosse J, Wehland M, Mann V, Reseland JE, Sundaresan A, Corydon TJ. The impact of microgravity on bone in humans. Bone. 2016;87: 44-56.

\section{Publisher's Note}

Springer Nature remains neutral with regard to jurisdictional claims in published maps and institutional affiliations.

Ready to submit your research? Choose BMC and benefit from:

- fast, convenient online submission

- thorough peer review by experienced researchers in your field

- rapid publication on acceptance

- support for research data, including large and complex data types

- gold Open Access which fosters wider collaboration and increased citations

- maximum visibility for your research: over $100 \mathrm{M}$ website views per year

At $\mathrm{BMC}$, research is always in progress.

Learn more biomedcentral.com/submissions 